\section{Original} Article

\title{
Cerebroprotective Effect of Piracetam in Patients Undergoing Open Heart Surgery
}

\author{
Sebastian Holinski, MD, ${ }^{1}$ Benjamin Claus, MD, ${ }^{1}$ Nour Alaaraj, MD, ${ }^{1}$ \\ Pascal Maria Dohmen, MD, PhD, ${ }^{1}$ Konrad Neumann, $\mathrm{PhD},{ }^{2}$ Ralf Uebelhack, MD, PhD, ${ }^{3}$ \\ and Wolfgang Konertz, MD, $\mathrm{PhD}^{1}$
}

\begin{abstract}
Objectives: Reduction of cognitive function is a possible side effect after the use of cardiopulmonary bypass (CPB) during cardiac surgery. Since it has been proven that piracetam is cerebroprotective in patients undergoing coronary bypass surgery, we investigated the effects of piracetam on the cognitive performance of patients undergoing open heart surgery.

Methods: Patients scheduled for elective open heart surgery were randomized to the piracetam or placebo group in a double-blind study. Patients received $12 \mathrm{~g}$ of piracetam or placebo at the beginning of the operation. Six neuropsychological subtests from the Syndrom Kurz Test and the Alzheimer's Disease Assessment Scale were performed preoperatively and on day 3, postoperatively. To assess the overall cognitive function and the degree of cognitive decline across all tests after the surgery, we combined the six test-scores by principal component analysis.

Results: A total of 88 patients with a mean age of 67 years were enrolled into the study. The mean duration of CPB was 110 minutes. Preoperative clinical parameters and overall cognitive functions were not significantly different between the groups. The postoperative combined score of the neuropsychological tests showed deterioration of cognitive function in both groups (piracetam: preoperative $0.19 \pm 0.97$ vs. postoperative $-0.97 \pm 1.38, p<0.0005$ and placebo: preoperative $-0.14 \pm 0.98$ vs. postoperative $-1.35 \pm 1.23, p<0.0005)$. Patients taking piracetam did not perform better than those taking placebo, and both groups had the same decline of overall cognitive function $(p=0.955)$.

Conclusion: Piracetam had no cerebroprotective effect in patients undergoing open heart surgery. Unlike the patients who underwent coronary surgery, piracetam did not reduce the early postoperative decline of neuropsychological abilities in heart valve patients.
\end{abstract}

Key words: cardiac surgery, cardiopulmonary bypass, cognition disorders, neuroprotective agents, cardiopulmonary bypass

\section{Introduction}

Cardiac surgery with the use of cardiopulmonary bypass $(\mathrm{CPB})$ is commonly performed nowadays. There are open heart procedures like valve surgery and operations without the need to open a cardiac chamber or a main vessel during coronary surgery. Cognitive impairments can be observed in many patients after both kinds
${ }^{1}$ Department of Cardiovascular Surgery, Charité Hospital, Medical University, Berlin, Germany

${ }^{2}$ Department of Biometry, Charité Hospital, Medical University, Berlin, Germany

${ }^{3}$ Department of Psychiatry, Charité Hospital, Medical University, Berlin, Germany
Received: February 4, 2010; Accepted: February 12, 2010 Corresponding author: Sebastian Holinski, MD. Department of Cardiovascular Surgery, Charité Hospital, Medical University, Schumannstr. 20/21, Berlin 10117, Germany

Email: sebastian.holinski@charite.de

(C)2011 The Editorial Committee of Annals of Thoracic and Cardiovascular Surgery. All rights reserved. 
of operations. ${ }^{1-3)}$ These cerebral disturbances vary in extent and duration, and they can reduce quality-of-life for a long time. ${ }^{4,5)}$ Furthermore, they increase in-hospital mortality, length of stay, and the use of resources. ${ }^{6}$ )

Different operative and patient-related factors are suspected to cause the postoperative cognitive decline. Hypoperfusion states, toxic influence of narcotics and other mechanisms are involved in the cognitive changes, ${ }^{7,8)}$ and furthermore, microembolism from the extracorporeal circuit and air in opened hearts seems to be causative. Attempts have been made to eliminate or reduce these causative mechanisms. Piracetam with its wellknown memory enhancing capacity, particularly in senile dementia, ${ }^{8)}$ was successfully used in patients undergoing non-open heart surgery. It reduced the cognitive decline after coronary bypass surgery substantially. ${ }^{9-11)}$ These results encouraged us to evaluate the effect of piracetam on the cognitive function of patients undergoing open heart surgery.

\section{Methods}

\section{Study Design/Protocol}

A double-blind, placebo-controlled clinical trial was conducted according to the Principles of Good Clinical Practice. The study was approved by the institutional ethics committee of Humboldt University. Patients who were indicated for an elective open heart procedure were included if they gave their written informed consent. Patients were excluded from the study if they met any of the following criteria:

- Insulin-dependent diabetes mellitus

- Renal insufficiency requiring dialysis

- History of TIA, PRIND, or complete stroke

Patients were randomly assigned to the piracetam group or control group. At the beginning of the operation, they received an intravenous infusion of $12 \mathrm{~g}$ piracetam/ $60 \mathrm{ml}$ or $60 \mathrm{ml}$ of saline over 30 minutes. Cognitive function was evaluated the day before surgery and on postoperative day 3 .

\section{Neuropsychological Assessment}

Patients were examined with a battery of neuropsychological tests for memory and attention that lasted approximately 20 minutes and consisted of the following 6 subtests of Syndrome Kurz Test (SKT) and Alzheimer's Disease Assessment Scale (ADAS). ${ }^{12)}$ Assessment took place at the bedside of the patient without any distraction.

$\mathrm{S}_{1}$ Immediate pictured object recall. Twelve pictures are shown within 20 seconds, and then the patient is asked to recall as many pictures as possible.

$\mathrm{S}_{2}$ Immediate word recall. 10 words are shown, each for 2 seconds, and then the patient is asked to recall as many words as possible.

$\mathrm{S}_{3}$ Attention. The patient is asked to perform a counting task as quickly as possible.

$\mathrm{S}_{4}$ Letter interference. The patient is asked to perform a reading task as quickly as possible.

$\mathrm{S}_{5}$ Delayed pictured object recall. Patient is requested to recall as many pictures from $S_{1}$ after a delay of 10 minutes.

$\mathrm{S}_{6}$ Delayed picture recognition. Patient is requested to recognize as many pictures from $\mathrm{S}_{1}$ out of 24 pictures shown after a delay of 15 minutes.

Except for tests S3 and S4, lower scores mean poorer performance. The tests were performed in two parallel forms in order to minimize practice effects at the postoperative retest.

\section{Open Heart Surgery}

Patients were premedicated with benzodiazepines. General anesthesia was conducted with propofol or isoflurane, opiates and muscle relaxants. Median sternotomy and full heparinization were performed. In all cases, normothermic cardiopulmonary bypass was used after the ascending aorta and right atrium were cannulated. The aorta was cross clamped, and warm blood cardioplegic solution was infused via the aortic root or directly into the coronary ostia. Cardiac chambers were entered via an aortotomy for aortic valve cases or via a left atriotomy for mitral valve cases. In Ross operations, the right heart was opened as well, for the pulmonary valve harvest. A procedural overview is provided in Table $\mathbf{1}$.

The aortic clamp was released after deairing of the heart via an ascending aortic vent catheter supported by lung inflation and cardiac massage. The heart usually started beating spontaneously. Continuous ventilation was started, and the patient was weaned from CPB. The chest was closed, and the patient was transferred to the intensive-care unit (ICU).

\section{Statistics}

Statistical analysis was done with SPSS ${ }^{\circledast} 14.01$ (SPSS Inc., Chicago, USA). The level of significance was $\alpha=0.05$.

To assess the overall cognitive function and the degree of cognitive decline across all tests after surgery, we combined the six test-scores by principal component analysis. 
Table 1 Overview of open heart procedures performed

\begin{tabular}{lccc}
\hline & All patients & Verum & Placebo \\
\hline Procedure & $\mathrm{N}$ & $\mathrm{N}$ & $\mathrm{N}$ \\
Biological AVR & 39 & 22 & 17 \\
Biological AVR + CABG & 12 & 6 & 6 \\
Mechanical AVR & 1 & 1 & 0 \\
Mechanical AVR + CABG & 2 & 1 & 1 \\
Ross operation & 16 & 7 & 9 \\
Ross operation + CABG & 1 & 0 & 1 \\
Refixation of AV-prosthesis & 1 & 1 & 0 \\
Biological MVR & 9 & 4 & 5 \\
Mechanical MVR & 4 & 2 & 2 \\
MV repair & 3 & 0 & 3 \\
$\sum$ & 88 & 44 & 44 \\
\hline
\end{tabular}

AVR, aortic valve replacement; CABG, coronary artery bypass grafting; AV, aortic valve; MVR, mitral valve replacement; $\mathrm{MV}$, mitral valve
Table 2 Association with cognitive development $S_{\text {post }}$

\begin{tabular}{lc}
\hline Variable & p-value \\
\hline Model & $<0.0005$ \\
$\mathrm{~S}_{\text {prae }}$ & $<0.0005$ \\
Age & 0.037 \\
Calcif. lesion & 0.434 \\
CPB time & 0.660 \\
OP time & 0.308 \\
Study group (Piracetam vs. Placebo) & 0.524 \\
\hline
\end{tabular}

$\mathrm{CPB}$, cardiopulmonary bypass; $\mathrm{OP}$, operation

Table 3 Demographic and operative data

\begin{tabular}{|c|c|c|c|c|}
\hline Variable & $\begin{array}{c}\text { All patients } \\
\text { Mean, Range, SD }\end{array}$ & $\begin{array}{c}\text { Piracetam } \\
\text { Mean, Range, SD }\end{array}$ & $\begin{array}{c}\text { Placebo } \\
\text { Mean, Range, SD }\end{array}$ & $\begin{array}{c}\mathrm{p} \text { value } \\
\text { Piracetam vs Placebo }\end{array}$ \\
\hline Age (yrs) & $67.2,39-87,9.4$ & $68.3,39-87,8.5$ & $66.2,40-87,10.1$ & 0.447 \\
\hline Calcif. lesion (\%) & $74.4 \%$ & $67.4 \%$ & $81.4 \%$ & 0.138 \\
\hline CPB time (min) & $110,49-207,38.8$ & $111,58-195,39.9$ & $108,49-207,38.0$ & 0.816 \\
\hline OP time (min) & $193,120-325,49.0$ & $197,120-315,47.7$ & $190,120-325,50.6$ & 0.397 \\
\hline
\end{tabular}

$\mathrm{SD}$, standard deviation; $\mathrm{CPB}$, cardiopulmonary bypass; $\mathrm{OP}$, operation

$$
\begin{aligned}
\mathrm{S}_{\mathrm{pre}}= & 0.29^{*} \mathrm{z}_{1, \mathrm{pre}}+0.24^{*} \mathrm{z}_{2, \mathrm{pre}}-0.22^{*} \mathrm{z}_{3, \mathrm{pre}} \\
& -0.25^{*} \mathrm{z}_{4, \mathrm{pre}}+0.26^{*} \mathrm{z}_{5, \mathrm{pre}}+0.22^{*} \mathrm{z}_{6, \mathrm{pre}}
\end{aligned}
$$

is the first principal component of the standardized scores before operation (baseline), i.e.

$$
\mathrm{z}_{\mathrm{i}, \mathrm{pre}}=\frac{S_{i, p r e}-\mu\left(S_{i, p r e}\right)}{\sigma\left(S_{i, p r e}\right)} \mathrm{i}=1, \ldots, 6 .
$$

with $\mu\left(S_{i, p r e}\right)$ and $\sigma\left(S_{i, p r e}\right)$ the mean and standard deviation of $S_{i, p r e}$.

The same transformation was applied to the scores $S_{1, p o s t}, \ldots, S_{6, p o s t}$ after operation.

$$
\begin{aligned}
\mathrm{S}_{\text {post }}= & 0.29^{*} \mathrm{z}_{1, \text { post }}+0.24^{*} \mathrm{z}_{2, \text { post }}-0.22^{*} \mathrm{z}_{3, \text { post }} \\
& -0.25^{*} \mathrm{z}_{4, \text { post }}+0.26^{*} \mathrm{z}_{5, \text { post }}+0.22^{*} \mathrm{z}_{6, \text { post }}
\end{aligned}
$$

with

$$
\mathrm{z}_{\mathrm{i}, \text { post }}=\frac{S_{i, \text { post }}-\mu\left(S_{i, \text { pre }}\right)}{\sigma\left(S_{i, \text { pre }}\right)} \mathrm{i}=1, \ldots, 6 \text {. }
$$

Note, the mean $\mu\left(S_{i, p r e}\right)$ and standard deviation $\sigma\left(S_{i, p r e}\right)$ of the pre-operative sores are used in the transformation formula for the $\mathrm{z}_{\mathrm{i}, \text { post }}$.

Association of $S_{\text {post }}$ with age, decalcification procedure, $\mathrm{CPB}$ time, OP time and treatment group (Piracetam vs. placebo) was examined by a general linear model (Table 2). To adjust for baseline, we included $S_{\text {pre }}$ in the model.

Moreover, age, decalcification procedure, CPB time, and OP time between the groups were tested by the Mann-Whitney U test (Table 3). Changes in the scores (preoperative minus postoperative) were also compared by the Mann-Whitney-U test, and comparisons of preoperative and postoperative scores within the treatment groups were conducted by Wilcoxon tests for paired samples (Table 4).

\section{Results}

A total of 88 patients (mean age of $67 \pm 9.4$ years) were included in the study. The mean time of patients on cardiopulmonary bypass was $110 \pm 39$ minutes. Placebo and piracetam groups were comparable in terms of age, decalcification procedures, CPB and OP time, indicating a homogenous study sample (Table 3). Of these parameters, only age was significantly associated with the perioperative development of cognitive function $(\mathrm{p}=0.037)$. Piracetam did not have an impact on cognitive develop- 
Table 4 Comparison of cognitive test results $(\mathbf{P}-=$ Placebo, $\mathbf{P}+=$ Piracetam $)$

\begin{tabular}{|c|c|c|c|c|c|}
\hline Variable & Group & $\begin{array}{c}\text { Preop } \\
\text { Mean } \pm \text { SD }\end{array}$ & $\begin{array}{c}\text { Postop } \\
\text { Mean } \pm \text { SD }\end{array}$ & $\begin{array}{c}\mathrm{p} \text { value } \\
\text { Preop vs Postop }\end{array}$ & $\begin{array}{c}\mathrm{p} \text { value } \\
\text { Preop-Postop: } \mathrm{P}-\text { vs } \mathrm{P}+\end{array}$ \\
\hline \multirow[t]{2}{*}{ Immediate pictured object recall } & $\mathrm{P}-$ & 5.4 (1.4) & 4.4 (1.4) & 0.001 & 0.761 \\
\hline & $\mathrm{P}+$ & 5.9 (1.9) & $4.8 \quad(1.7)$ & $<0.0005$ & \\
\hline \multirow[t]{2}{*}{ Delayed pictured object recall } & $\mathrm{P}_{-}$ & $5.2(2.0)$ & $3.6(2.0)$ & $<0.0005$ & 0.403 \\
\hline & $\mathrm{P}+$ & $5.7 \quad(2.2)$ & $3.7 \quad(2.1)$ & $<0.0005$ & \\
\hline \multirow[t]{2}{*}{ Delayed picture recognition } & $\mathrm{P}-$ & 10.3 (1.6) & $8.4 \quad(2.3)$ & $<0.0005$ & 0.732 \\
\hline & $\mathrm{P}+$ & 10.8 (1.3) & $8.9 \quad(2.5)$ & $<0.0005$ & \\
\hline \multirow[t]{2}{*}{ Immediate word recall } & $\mathrm{P}_{-}$ & $5.5 \quad(1.7)$ & $4.5 \quad(1.7)$ & 0.001 & 0.341 \\
\hline & $\mathrm{P}+$ & $5.6(1.8)$ & $5.0(1.6)$ & 0.057 & \\
\hline \multirow[t]{2}{*}{ Letter interference } & $\mathrm{P}_{-}$ & $26.2(7.1)$ & $32.3(10.4)$ & $<0.0005$ & 0.558 \\
\hline & $\mathrm{P}+$ & $26.6(7.3)$ & 32.6 (11.2) & $<0.0005$ & \\
\hline \multirow[t]{2}{*}{ Attention } & $\mathrm{P}-$ & 19.7 (6.4) & $26.3(9.0)$ & $<0.0005$ & 0.429 \\
\hline & $\mathrm{P}+$ & $18.5 \quad(5.4)$ & $23.6 \quad(7.1)$ & $<0.0005$ & \\
\hline \multirow[t]{2}{*}{ Overall cognitive function } & $\mathrm{P}-$ & $-0.14(0.98)$ & $-1.35(1.23)$ & $<0.0005$ & 0.955 \\
\hline & $\mathrm{P}+$ & $0.19(0.97)$ & $-0.97(1.38)$ & $<0.0005$ & \\
\hline
\end{tabular}

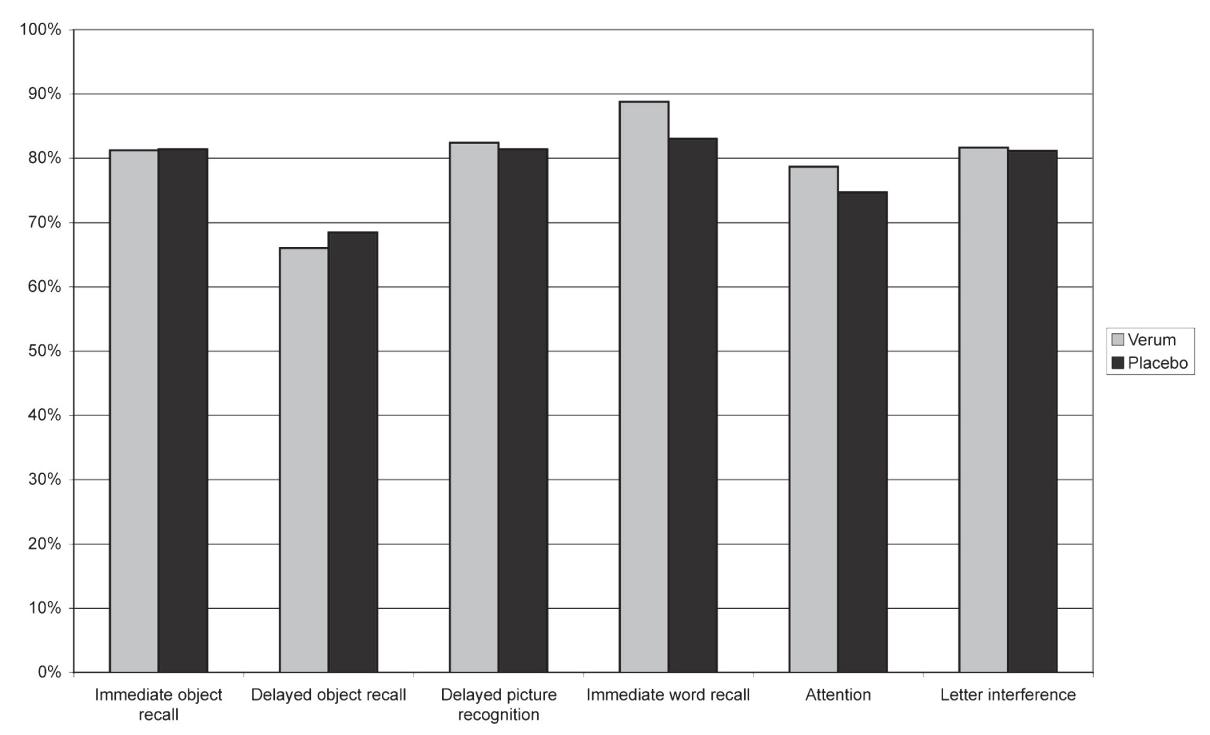

Fig. 1 Postoperative test results of both groups compared to baseline (100 percent).

ment (Table 2).

Preoperative overall cognitive function was similar in both groups (piracetam: $0.19 \pm 0.97$ vs. placebo: $-0.14 \pm$ $0.98, \mathrm{p}=0.231$ ). Comparison of postoperative versus preoperative testing revealed a significant decline of overall test results in both groups (piracetam: preoperative $0.19 \pm$ 0.97 vs. postoperative $-0.97 \pm 1.38, \mathrm{p}<0.0005$ and placebo: preoperative $-0.14 \pm 0.98$ vs. postoperative $-1.35 \pm$ $1.23, \mathrm{p}<0.0005)$. Comparison of the postoperative performance of both groups did not show statistically significant differences in either group $(p=0.113)$. Furthermore, analysis of the cognitive change (preoperative minus postoperative) revealed that the decline of overall cogni- tive function did not differ significantly between the groups ( $p=0.955$ ), see Table 4. Overall cognitive results reflected the results of the subtests. All subtests of both treatment groups showed a postoperative decline in the cognitive function of patients, compared to the baseline (Fig. 1).

\section{Discussion}

Cognitive decline was frequently detected after cardiac surgery procedures with CPB and can be of clinical relevance. ${ }^{1-3)}$ Piracetam, a drug approved for treatment of senile dementia, proved to be neuroprotective in patients 
undergoing coronary bypass surgery. ${ }^{9-11)}$ Since this operation is performed on the surface of the heart, there is no need to open a cardiac chamber apart from right atrial canulation. However, standard aortic and mitral valve surgery is performed within the opened left heart. Cerebral microembolism from intracardiac air, as well as debris from resected calcified valves, potentially contributes to the observed cognitive decline after the operation. This present study was conducted to evaluate the cerebroprotective effect of piracetam in patients who underwent open heart surgery.

Considering the early postoperative situation of the patient, we selected neuropsychological tests with tasks that require a minimum of motor activity. A brief battery of neuropsychological tests for quantifying verbal and non-verbal short term memory and attention were used. Other cognitive functions may also be affected by the surgery, but because of the limited cooperation of patients, a selection of psychometric instruments had to be made. Most of them were chosen from the repeatable test battery SKT. It is a standardized screening instrument designed to assess cognitive function in a brief administration. ${ }^{12}$

In contrast to our previous studies of coronary patients, a bolus infusion of piracetam at the beginning of the operation did not reduce the decline of cognitive function, early after open heart surgery. Two reasons are possible to explain this observation. First, we might not have administered piracetam long enough for it to have an impact. A longer application of the drug might be crucial. Some coronary patients have been treated for up to six weeks after surgery. ${ }^{10)}$ Therefore, further work should be done to evaluate if piracetam is cerebroprotective in valve patients after a prolonged intake of the drug. Second, piracetam may not cerebroprotective during open heart surgery because of other brain damaging mechanisms, compared to those of isolated coronary surgery, namely, air or/and valve debris embolism. Of course, the properties of piracetam that work to achieve neuronal protection are well documented. It improves red blood cell deformity and thereby oxygen supply. ${ }^{13)}$ Furthermore, piracetam normalizes a hyperreactive platelet function which reduces the risk of thromboembolism. ${ }^{14}$ Moreover, it is assumed that piracetam provides the neuron with better protection against oxidative stress by normalizing membrane-associated cell activity. ${ }^{15)}$ However, the cerebral changes associated with valvular surgery might be out of reach of piracetam at least when applied like in the present study.
Apart from piracetam the present study also evaluated the influence of age, duration of $\mathrm{CPB}$, operation duration and calcified valve disease on the cognitive performance. Only age was associated with changes in cognitive function. Younger patients seem less prone to a perioperative cognitive decline than are older patients. The duration of $\mathrm{CPB}$ does not affect cognitive function, though $\mathrm{CPB}$ is known to lead to cerebral microembolism, ${ }^{7,16,17)}$ which is similar to what we had observed in a previous study. Interestingly, the operation on a calcified valve did not have an influence on cognitive performance either. This might be due to a meticulous intraoperative technique to remove debris.

In summary, pre surgical administration of piracetam did not prevent the post surgical decline of cognitive function in older patients who underwent open heart surgery. Long-term use of piracetam in these patients should be investigated.

\section{References}

1) Newman MF, Kirchner JL, Phillips-Bute B, Gaver V, Grocott $\mathrm{H}$, et al. Longitudinal assessment of neuropsychological function after coronary-artery bypass surgery. N Engl J Med 2001; 344: 395-402.

2) Andrew MJ, Baker RA, Bennetts J, Kneebone AC, Knight JL. A comparison of neuropsychological deficits after extracardiac and intracardiac surgery. $\mathrm{J}$ Cardiothorac Vasc Anesth 2001; 15: 9-14.

3) Ebert AD, Walzer TA, Huth C, Herrmann M. Early neurobehavioral disorders after cardiac surgery: a comparitive analysis of coronary artery bypass graft surgery and valve replacement. J Cardiothorac Vasc Anesth 2001; 15: 15-9.

4) McKhann GM, Goldsborough MA, Borowicz LM Jr, Selnes OA, Mellits ED, et al. Cognitive outcome after coronary artery bypass: a one-year prospective study. Ann Thorac Surg 1997; 63: 510-5.

5) Bruggemans EF, Van Dijk JG, Huysmans HA. Residual cognitive dysfunctioning at 6 months following coronary artery bypass graft surgery. Eur J Cardiothorac Surg 1995; 9: 636-43.

6) Roach GW, Kanchuger M, Mangano CM, Newman M, Nussmeier N, et al. Adverse cerebral outcomes after coronary bypass surgery, Multicenter Study of Perioperative Ischemia Research Group and the Ischemia Research and Education Foundation Investigators. N Engl J Med 1996; 335: 1857-63.

7) Diegler A, Hirsch R, Schneider F, Schilling LO, Falk V, et al. Neuromonitoring and neurocognitive outcome in off-pump versus conventional coronary artery bypass operation. Ann Thorac Surg 2000; 69: 1162-6.

8) Waegemans T, Wilsher CR, Danniau A, Ferris SH, Kurz A, et al. Clinical efficacy of piracetam in 
cognitive impairment: a meta-analysis. Dement Geriatr Cogn Disord 2002; 13: 217-4.

9) Uebelhack R, Vohs K, Zytowski M, Schewe HJ, Koch $\mathrm{C}$, et al. Effect of piracetam on cognitive performance in patients undergoing bypass surgery. Pharmacopsychiatry 2003; 36: 89-93.

10) Szalma I, Kiss A, Kardos L, Horvath G, Nyitrai E, et al. Piracetam prevents cognitive decline in coronary artery bypass: a randomized trial versus placebo. Ann Thorac Surg 2006; 82: 1430-5.

11) Holinski S, Claus B, Alaaraj N, Dohmen PM, Kirilova K, et al. Cerebroprotective effect of piracetam in patients undergoing coronary bypass surgery. Med Sci Monit 2008; 14: 153-7.

12) Kim YS, Nibbelink DW, Overall JE. Factor structure and scoring of the SKT test battery. J Clin Psychol 1993; 49: 61-71.
13) Müller WE, Eckert GP, Eckert A. Piracetam: Novelty in a unique mode of action. Pharmacopsychiatry 1999; 32 Suppl 1: 2-9.

14) Moriau M, Crasborn L, Lavenne-Pardonge E, von Frenckell R, Col-Debeys C. Platelet anti-aggregant and rheological properties of piracetam. Drug Res 1993; 43: $110-8$.

15) Peuvot J, Schanck A, Deleers M, Brasseur R. Piracetam-induced changes to membrane physical properties. Biochem Pharmacol 1995; 50: 1129-34.

16) Taggart DP, Westaby S. Neurological and cognitive disorders after coronary artery bypass grafting. Curr Opin Cardiol 2001; 16: 271-6.

17) Sylivris S, Levi C, Matalanis G, Rosalion A, Buxton $\mathrm{BF}$, et al. Pattern and significance of cerebral microemboli during coronary artery bypass grafting. Ann Thorac Surg 1998; 66: 1674-8. 